\title{
¿ La Isla de los Monos de Róger Lindo
}

Allan Barrera
Universidad de El Salvador

La Isla de los Monos, publicada el pasado 06 de diciembre de 2016 por UCA Editores, es la segunda novela del poeta salvadoreño Roger Lindo. La primera fue El Perro en la Niebla (2006) que es, a mi juicio, una de las mejores novelas que se han escrito en los últimos años y quizá de las menos estudiadas por la crítica literaria y cultural centroamericana.

La Isla de los Monos es una historia narrada desde la perspectiva y subjetividad de "Cacho", un adolescente de 13 años de edad, perteneciente a una familia de clase media urbana, en San Salvador de finales de los años 60. Cacho conoce a "Lupita", una compañera con mucho ímpetu de libertad, y juntos van descubriendo y explorando las posibilidades de su propia vida y de su libertad en cada uno de los espacios que se mueven: el colegio, la ciudad, la casa familiar. Esto en medio de la violencia política y el militarismo propio de la época. Un día deciden retar al orden establecido y comienzan el juego peligroso de repartir mensajes en contra del gobierno, lo cual se convierte en una aventura sin retorno.

La novela puede tener varias interpretaciones, eso dependerá de cada lector y las mediaciones que se establezcan con el texto. Aquí presento algunas reflexiones posibles.

A nivel formal, la novela tiene una extensión de 201 páginas y está estructurada en 21 capítulos. La portada tiene una imagen de una laguna de agua verdosa y una banca vacía, las cuales hacen referencia a la laguna y a la isla en la que viven los monos del zoológico de San Salvador. La historia está contada en primera persona desde la focalización de un narrador personaje protagonista o narrador homodiegético (Cacho). La estructura de la historia presenta una cadena de acontecimientos ordenados de manera coherente, regidos por la sucesividad y 
causalidad. El tiempo de la diégesis es lineal que no presenta saltos o giros inesperados para el lector, y a nivel discursivo predomina el estilo directo.

Es notable que Roger Lindo tiene un claro dominio del lenguaje y de sus posibilidades. Además, puesto que él ha cultivado la poesía toda su vida, se percibe el uso de algunas figuras literarias propias del género lírico que enriquecen la narración con una prosa poética.

La novela inicia con un epígrafe de una de las grandes composiciones de Pink Floyd, la canción "Shine on You Crazy Diamond", que dice: "Remember when you were young / you shone like the sun" (en español: "Recuerda cuando eras joven / que tú brillabas como el sol”). El epígrafe musical está colocado ahí para anunciar al lector, o más bien para invitarle a que se sitúe frente al texto desde una mirada nostálgica que rememora la juventud, como ese lugar de posibilidades donde las cosas siempre parecen acontecer por vez primera.

El epígrafe también nos anuncia lo que luego se convierte en una presencia constante de intertextos y citas musicales en la novela: Brahms, Chopin, Berlioz, The Who, Buffalo Springfield, Strawbeery Alarm Clock, The Rascals, Paul Anka, entre otros, que trazan un mapa del consumo cultural de la época en la que se sitúa la historia. Y en ese sentido, Lindo no sólo refleja el ambiente cultural de la época sino que también revela las particularidades de cierta clase media urbana de San Salvador que muy poco conocíamos.

La novela es eminentemente urbana. Lindo traza una cartografía de la ciudad a partir de las trayectorias y movimientos de Cacho y Lupita, quienes siempre están desplazándose de un lugar a otro. La mayor parte de sus acciones tienen como macroespacio el área metropolitana de San Salvador. Aparecen numerosos topónimos como: los barrios San Jacinto, La Vega y San Esteban, las calles Madrid, Modelo y Lara, los portales de la Dalia, el parque Hula Hula, el cine México, el bulevar Venezuela y del Ejército, la avenida España, el Zoológico, el río Acelhuate, la Universidad de El Salvador, y otros lugares que ya no existen en el actual San Salvador. En ese sentido, la novela cumple la función de recolectar lugares olvidados y ciertos restos de la ciudad que ésta ha tirado o despreciado con el pasar del tiempo y con la indiferencia de sus gobernantes y su gente. De esta manera, Lindo presenta una estampa literaria que nos invita a mirar con otros ojos y con otra mirada capaz de develar la belleza oculta que tienen los lugares y los espacios de la ciudad y el centro de San Salvador. 
Este punto me parece importante porque al igual que en su novela anterior, El perro en la niebla, Lindo demuestra, por un lado, que tiene una capacidad maestra de reconstruir paisajes urbanos y elaborar una poética de los espacios en los que coloca a sus personajes, y por el otro, el sentido de pertenencia y cariño que le siente a la ciudad de San Salvador. Ésta ocupa un lugar central en la trama al mismo nivel que los personajes.

Además, dedica muchas páginas a explorar y exponer las relaciones interpersonales y las disputas de los sujetos que suceden en los microespacios: la familia, el colegio, las librerías, el zoológico, entre otros, presentando así un retrato muy rico y novedoso de la ciudad.

\section{La destrucción del archivo}

Lindo sitúa la historia de la novela a finales de la década de los 60, en un tiempo de gestación y maduración de las condiciones que desembocaron en la catástrofe que tuvo como centro el enfrentamiento armado entre el Ejército salvadoreño y la guerrilla (1980-1992). Si bien, se delinea la atmósfera de violencia política y militarismo como formas de gobierno autoritario, los protagonistas no asumen una actitud heroica o un tono de denuncia que sea evidente, a la manera como se hacía desde lanovela de la estética del compromiso o de la producción literaria centroamericana y latinoamericana de la segunda mitad del siglo XX, a la que muchos enmarcaron dentro del paradigma estético testimonial-realista.

Cacho y Lupita, motivados más por la aventura de iniciar un juego peligroso que por la reflexión política, comienzan generando pequeñas acciones en contra del gobierno autoritario, y luego ya es demasiado tarde para echarse para atrás. Es un juego que no tiene retorno, y sus acciones -al menos en el caso de Cacho- terminan siendo más radicales.

El Salvador es representado como un país gobernado por pistoleros y abogados, y en ese sentido, el joven protagonista cuestiona la manera cómo el poder solía legitimarse por quienes detentan los medios de destrucción masiva, es decir, las armas - que ya habían sido probadas en el levantamiento y masacre de 1932 - y los mecanismos legales instituidos en el aparato de Estado. 
Para no ir tan lejos, cada sociedad, si es democrática, se rige por una norma suprema: su Constitución. Aunque en países parecidos a los nuestros... todavía se usan las dos cosas: pistoleros y abogados. Fijate bien: a la par de cada junta militar o de cada coronelote que han mandado en el país desde 1931, siempre hay un abogado haciéndole guardia... "Tapón", nuestro actual presidente, era militarote. Cuestas, el vicepresidente, era abogado. El presidente anterior, Rivera, también era chafa. Lima, su vicepresidente, abogado. José Enrique tenía razón. Pistoleros. Abogados. Comprendí que los militares eran los culpables de que la clase de Música en la escuela fuera en realidad una clase de himnos. (Lindo, 2016, p. 46)

Si bien hay un cuestionamiento al militarismo como forma de gobierno autoritario en el que las instituciones ejecutivas, legislativas y judiciales son controladas por las fuerzas armadas que impiden cualquier forma de control democrático, también lo hay hacia la rigidez y jerarquía de las relaciones de poder que se establecen en la organización revolucionaria.
Cacho, el protagonista, establece una diferencia entre la organización oficial y la informal/autoconstruida a la que él pertenece. La oficial está organizada de manera vertical y jerárquica, en cambio la que él y Lupita construyen, solamente está integrada por ellos dos. Ellos se consideran un equipo paralelo, independiente, en el que no existen las jerarquías de poder.

La organización revolucionaria tampoco es exenta de la crítica;

A los repartos "oficiales", es decir, los que llevaban a cabo grupos comoeldeJoséEnrique-conrecursos infinitamentesuperiores alos nuestros-, ahora se añadían los nuestros. Lupita y yo integrábamos un equipo paralelo, independiente. Tiene sus ventajas una organización como la nuestra: dos personas, una máquina de escribir, no se necesitan jefes, las luchas de poder no existen, no hay necesidad de explotar o engañar a nadie, ni siquiera la de tener un nombre o un himno. (Lindo, 2016, p. 173)

Cacho y Lupita inician un volanteo sin pedir permiso ni rendirle cuentas a nadie. Para ellos, se trata de una utopía distinta en la que el poder y la disciplina ya no se establece a partir de jerarquías 
aun cuando exista una causa "justa" que la legitime.

Asimismo, hay un cuestionamiento a las buenas intenciones de querer cambiar el estado de cosas sin un cambio radical. Cando el hermano del protagonista, joven universitario revolucionario que estudia Derecho en la UES y comprometido con la causa, le intenta explicar al protagonista cómo opera el militarismo y cómo podría ser cambiado a través de los mecanismo instituidos, el protagonista le responde con cierto escepticismo:

Nuestra constitución es fundamentalmente buena, progresista. - Le dice el hermano- Ahora, que no se la respete es otra cosa... Por consiguiente, en el momento de descubrir un rectángulo de estacionamiento vacío, quedan aún espacios para aplicar la ley... ayudar a la gente miserable. La jurisprudencia labora. (Lindo, 2016, p. 47)

A lo que el protagonista responde:

No quise dejarle acabar, llegar a la parte del discurso en que de seguro diría que es posible recibirse de abogado y dedicarse a pelear por una causa noble y justa, en lugar de hacerle guardia a los militares. Estudiaba Derecho. Era lo que lo atraía, y punto. Uno nunca sabe cómo va a terminar un estudiante pasadas las calenturas idealistas. (Lindo, 2016, p. 47)

La novela propone alegóricamente el fuego para destruir el poder instituido que se reproduce desde las instituciones. Primero, el protagonista incendia el aula del colegio donde fue educado desde que era niño y luego los archivos de la sección de Investigaciones Delictivas de la Policía Nacional al interior del Castillo. Un fuego que sugiere, metafóricamente, la destrucción de las cosas para comenzar de cero. Se queman los archivos polvorientos en los que descansan las demandas y los expedientes de las víctimas del Estado porque la justicia ha fallado. El Estado es el victimario y no puede procurarle justicia a quienes él mismo injuria.

Al final de un largo corredor de ladrillos antiguos y opacos, di con un gran cuadro de Tapón, el presidente del país. No pude contener la risa, por fortuna me encontré una habitación vacía a la par, a la que entré para comedirme. Estaba llena de expe- 
dientes apilados, aplastados, montañas de denuncias semejantes a la que yo acababa de presentar infructuosamente. Archivos polvorientos que aparentemente nadie tocaba en meses, años quizá. Me instalé en un pupitre pero no encontré ninguna esvástica. Me resistí a pensar en las cosas lindas de la vida. En vez de eso, evoqué escenas de caos, de combate, de penosos arrastres en el lodo y la oscuridad, como las de la película "El día más largo del siglo", que mi madre me llevó a ver a los cinco años. Al cine Modelo, para variar. Vacié el resto del combustible sobre los expedientes y les prendí fuego. (Lindo, 2016, p.193)

La novela cierra con la salida de Cacho en lancha hacia Nicaragua en busca del exilio, resultado del incendio que provocó en el colegio y en el Castillo de la policía. Al pasar la lancha frente a una isla del golfo, Cacho encuentra a unos monos cuyo parecido le recuerdan a los monos del zoológico de San Salvador con quienes establece un diálogo. "Me llamo Cacho Leiva, acabo de hacer lo más atrevido que una persona puede hacer, y voy solo por el mundo" (Lindo, 2016), les dice.
A lo que uno de ellos le responde: "la única manera de seguir adelante es renunciar a todo... Aprende a vivir en el mundo real" (Lindo, 2016). Esta escena absurda de un mono aconsejando a un niño de 13 años para que renuncie a todo y que aprenda a vivir en el mundo real podría interpretarse, quizá, como un cuestionamiento a la realidad. A lo real que esconde mucha irracionalidad que conduce a los sujetos a estadios de destrucción y violencia.

\section{Conclusión}

La Isla de los Monos propone, de algún modo, un espacio crítico para el cuestionamiento y la reevaluación crítica de los dos grandes proyectos políticos que determinaron el siglo $X X$ y que en su momento fueron incuestionables por sus promotores. Al exponer algunas contradicciones y la violencia ejercida por el Estado autoritario y las respuestas de los sujetos que lo padecen, contribuye al entendimiento de esos sucesos de finales de los 60 que derivaron en el enfrentamiento armado en los 80 , aportando un conocimiento acerca de las experiencias del daño. Asimismo, muestra y produce las experiencias que muchos no conocíamos de la vida cotidiana de ese periodo y que la historia, preocupada por relatar los grandes sucesos producidos por los grandes actores, no logra contar.

Roger Lindo desde esta novela aporta a la literatura de ficción en 
su función de hacer memoria y de mostrar otras visiones de nuestro pasado, capaces de mejorar el entendimiento y comprensión de nuestra sociedad en el presente para tener una mejor mirada hacia el futuro. Porque para poder edificar una sociedad verdaderamente demo- crática en una que está todavía en proceso de saneamiento después de una guerra y una dictadura militar es necesario permitir, reconocer y respetar todas las diferentes memorias y las diversas interpretaciones que existen sobre el pasado.

\section{Referencias}

- Cortez, B. (2009). Estética del cinismo. Pasión y desencanto en la literatura de posguerra. Guatemala: F\&G editores.

- Lindo, R. (2016). La Isla de los Monos. San Salvador: UCA. Editores.

- Lindo, R. (2006). El perro en la niebla. Madrid: Editorial verbigracia. 